\title{
Self- Checkout Service with RFID Technology in Supermarket
}

\author{
$\mathrm{Ng} \mathrm{Xin} \mathrm{Jie}^{1, *}$ Intan Farahana Binti Kamsin ${ }^{2}$ \\ ${ }^{1,2}$ Asia Pacific University of Technology and Innovation, Technology Park Malaysia, Bukit Jalil, Kuala Lumpur, \\ Malaysia. \\ *Corresponding author.Email:tp055463@mail.apu.edu.my
}

\begin{abstract}
The self-checkout service system has appeared and has gradually become popular all over the world nowadays. The main purpose of the self-checkout service system is to save staff costs and speed up the customer's shopping process. However, according to a number of studies, the self-checkout service system is causing an increase in thefts, and this causes huge losses for businesses. Therefore, this research aims to implement radio frequency identification (RFID) technology to selfcheckout service systems to solve the problem of increased thefts caused by the implementation of self-checkout services in supermarket. For this study, it was decided to use systematic sampling and submit a survey to every fifth customer who left the supermarket until the survey results of 100 customers were collected. Using this latest RFID technology in the selfcheckout system can make the supermarket without suffering additional losses. This RFID technology is implemented with the help of RFID tags and RFID readers, which are similar to the functions of general bar codes and bar code scanners on the market, but they are safer to avoid theft. In addition, this article also studies how to use RFID to help reduce the waiting time for checkout, which can scan the entire area of goods in a few seconds, which is suitable for inventory, checkout and simplifying the process.
\end{abstract}

Keywords: Anti-theft, Internet of Things Technology (IOT), RFID, Self-checkout system, Supermarket.

\section{INTRODUCTION}

Self-checkout service systems have emerged and are gradually becoming popular worldwide. The system allows consumers to complete the purchase process without the help of retailer personnel [12] [45] which also reduce business costs because customers can perform the checkout by themselves, so the cashier can take care of several counters, thereby reducing labor costs. Merchants introduced the self-service checkout system is to reduce labor costs and speed up the customer checkout process. However, recent studies have found that because merchants use a self-checkout system, the annual income does not increase but decreases. [3] According to a study conducted by The New York Times on self-checkout kiosks in the United States, the United Kingdom, the Netherlands, and Belgium, self-checkout technology increases the possibility of shoplifting. [20] After investigation and statistics, in addition to external theft and internal theft, daily customers (customers who usually do not steal in any other way) often embezzle during self-checkout are also the biggest reason. [14] This is because the self-checkout system reduces the monitoring of checkout products, which increases the possibility of theft, which in turn causes the company to pay higher fees. [3] [46-50]. Besides that, many research reports show that more and more people have been thief in the self-checkout center store consciously or unconsciously. [24] For example, there is a survey by VoucherCodesPro.co.uk for 2634 adults shows that $20 \%$ of people admitted that they had stolen during self-checkout, and more than half of them said that they did so because they could not scan items, so they just take things without paying. [22] This research proposes an improved selfcheckout system, which implements the latest RFID technology on the original system which can minimize the 
theft problem by its tracking technology. This study describes a study of self-checkout systems in supermarkets. This article will be divided into several parts. The first is the literature review, which will conduct a wide range of reading and understanding of the literature in the research field, and conduct a comprehensive analysis and review. The research on related issues is also discussed, including a further description of the purpose and objectives of this research and the research problem. This article also discusses how to conduct the research and what improvements can be brought to the industry as a result of the research. Finally, this article also summarizes the proposed system.

\section{RELATED WORK}

\subsection{Self-checkout System}

Nowadays, many retail stores and shopping malls in the world have introduced the self-checkout system. It is the system in a hardware so that customers can perform the checkout service by themselves [16], this system is more efficiency than the traditional checkout stations that need to operate by workers. It includes many components that similar to traditional checkout counters, which including components for scanning, packing, and bidding customer orders. [30] This invention is to reduce the time required for customers to process the purchased items and also reduce labor costs [51]. [15] Normally, customers can handle all the items that they want to purchase by themselves. They perform barcode scanning through a scanner and screen, and then make payments [52-54]. [1] Generally, there are two payment methods for selfcheckout system, either the shoppers print out the receipt at the scanning location, and takes it to the checkout clerk then completes the payment, or they can pay directly at the selfcheckout station, and the customers can choose to pay in cash or pay with credit. [29]

\subsection{RFID technology}

Radio Frequency Identification technology (RFID) is a new technology that uses radio waves to read and capture the information stored on the RFID tag carried by the object to identify and track the object. [18] The RFID system consists of 3 parts: (1) RFID tag, a microchip that can be embedded in physical products for storing and processing information, which contains a specific serial number (2) reader and its antenna, can receive and send signals to read the information on the RFID tag, such as serial number, location, color, date of purchase and so on. (3) Data processing system, to gather and filter all RFID tag data, then communicate with other supply chain information systems. [2][39] The entire data collection process is based on the electromagnetic wave exchange between these components. RFID tags are superior to barcodes because when using a barcode system, the operator must scan items one by one, and RFID readers can automatically receive information from multiple tags at the same time [19][25]. Besides, when used it for identification of objects, it also has faster response time and processing time, which has absolute advantages in many areas. It has a better security level compare with other tag such as barcode tag [10], so in many industries around the world, more and more organizations have been considering the introduction of RFID systems to improve its business and operational processes. [37] RFID can be mainly used for three purpose: asset management and tracking access control and automatic payments. [9] It has obvious benefits, such as reducing costs, time, human resources and preventing theft [36][43].

\subsection{Supermarket}

Since the 1990s, the importance of supermarkets in the world food economy has increased a lot. Now, they are not only the main buyers and sellers of food in developed countries, but also in developing countries. The term "supermarket" is used to denote a large self-service store that provides a variety of groceries, food and daily commodities classified by department. [11] Compared with traditional grocery stores, it has a larger size and a wider range of choices. It also sells goods that are usually found in convenience stores, but compared with hypermarket, its size smaller and also fewer types of goods to choose from it. [42] Supermarkets are generally run by a variety of commercial organizations, from wealthy locals to wellknown multinational companies, so their global procurement network, strict quality requirements and Strong financial resources enable them to provide consumers with relatively cheap but high-quality products [6].

\subsection{Self-Checkout Service with RFID technology in Supermarket}

The product information stored in the RFID tag can be retrieved through the RFID reader provided in the selfcheckout channel without having to access the lookup table to find product information. [5][30] RFID technology can identify thousands of items in a few seconds, RFID reader can capture all the relevant data of the items with RFID tags, and transmit the item information to the host system [4][20] [55,56, 57], this is the biggest advantage of using it in the sales industry, because if barcodes are used, all products purchased by customers must be scanned one by one. [39] With RFID, customers no longer need to remove groceries from the shopping cart and place them on a 
conveyor belt to be tracked for payment. [15] Generally, the self-checkout system also adds a payment function to enable shoppers to pay bills using various payment methods. That is very high risk when it is using barcode, but improving security is the biggest benefit of using RFID in a self-checkout system, as it provides real-time information about product movement and sounds an alarm to the security system when an unpaid product movement is detected. [16][44] In addition, some self-checkouts also uses RFID tag products to obtain and manage information about inventory levels in order to respond to customer needs in a timely manner. As RFID technology has the ability to provide the latest information about items, it can provide accurate information about inventory levels [9] In this way, merchants can also keep inventory levels to a minimum, which may result in lower inventory costs. [31] However, in Malaysia, few merchants adopt self-service technology. The implementation of the self-checkout system in Malaysia is still in its infancy, now there is only two Malaysia's supermarkets that have implemented selfcheckout system, one of them is Tesco IOI City, Putrajaya and another is Tesco KSL City, Johor Bahru and since the implementation of the system in Malaysia has not yet been exposed to RFID technology, the acceptance of the technology is still uncertain. [21]

\subsection{Systematic Review}

\subsubsection{Similar System}

\subsubsection{NCR SelfServ Checkout in Tesco Malaysia}

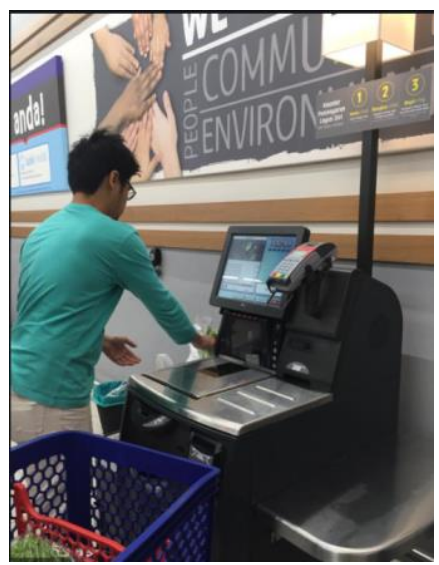

Figure 1 NCR SelfServ Checkout [35]

NCR SelfServ Checkout is a self-checkout system that launched by Tesco Malaysia and this technology is the first of its kind in Malaysia, which can guide customers to purchase goods by themselves by providing a touch screen throughout the process, thereby reducing queue time. [35] The system requires customers to scan barcodes one by one themselves, after that the system will enter the types of items such as fruits and vegetables and weigh and then customer can put all the items that already scanned by them into the "bagging area". [30] The machine's "bagging area" sensor will confirm the weight of the previously stored information to ensure that the correct item is bagged. Only when the observed weight matches the expected weight, the customer is allowed to continue paying. If customers do not have a credit or debit card, they can still pay in cash through the banknote scanner and coin slot at the self-checkout station. NCR is currently the leading provider of selfcheckouts and according to NCR's research shows that after consuming the system, the waiting time for customers can be reduced by up to $40 \%$. [30]

\subsubsection{Snabble}

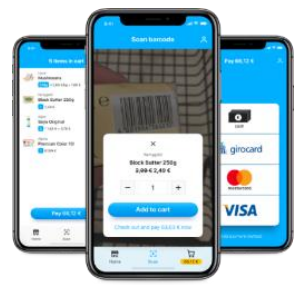

Figure 2 Snabble Application

Snabble is a well-known Scan\&Go application on the market, which is a self-checkout system based on a mobile phone application. Users only need to download the app, and no need to log in or register to use it. After customers have the app, in any participating store, they only need to open the app before putting the item in the shopping cart, click the scanner, scan the barcode of the item in front of the phone camera, and then add the item to the digital shopping cart. Then, customers can pay directly in the app via direct debit, credit card or PayPal if the retailer has supported it. Otherwise, they can also pay directly at regular checkpoints and self-checkout terminals. Currently, the application has announced cooperation with an IKEA that located in Germany in 2019. [34]

\subsubsection{Regi-Robo ${ }^{\mathrm{TM}}$ from Panasonic using in retail shop.}

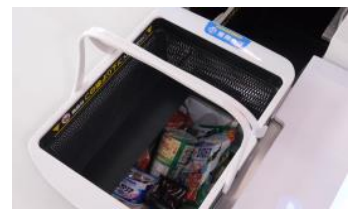

Figure 3 Regi-Robo ${ }^{\mathrm{TM}}$ [33]

Regi-Robo ${ }^{\mathrm{TM}}$ is a fully automatic checkout system that uses a special basket and RFID tags, so that customers do not need to scan the purchased items one by one before 
payment, achieving faster checkout. When using the RegiRobo $^{\text {TM }}$ system, customers can directly pick-up items that already implement with RFID tags and put them into a shopping basket, and then walk with the shopping basket through a special checkout channel for automatic checkout. The system will automatically scan all products which having RFID tags, and then display the price and total of all items on the screen for customers to pay, thereby significantly shortening the checkout time. This also greatly reduces staff operations and saves store labor. In February 2017, Lawson and Panasonic collaborated on the first experimental demonstration of Regi-Robo(R) in Japan. [33]

Table 1. Comparison between NCR SelfSery, Snabble and Regi-Robo ${ }^{\mathrm{TM}}$

\begin{tabular}{|l|l|l|l|}
\hline Features & $\begin{array}{l}\text { NCR } \\
\text { SelfServ }\end{array}$ & Snabble & $\begin{array}{l}\text { Regi- } \\
\text { Roborm }^{\text {TM }}\end{array}$ \\
\hline Tag & Barcode & Barcode & RFID \\
\hline Efficiency & Low & Normal & High \\
\hline $\begin{array}{l}\text { Line of } \\
\text { sight }\end{array}$ & Required & Required & $\begin{array}{l}\text { Not } \\
\text { Required }\end{array}$ \\
\hline $\begin{array}{l}\text { Security } \\
\text { Level }\end{array}$ & Low & Low & High \\
\hline $\begin{array}{l}\text { Mobile } \\
\text { App }\end{array}$ & No & Yes & No \\
\hline $\begin{array}{l}\text { Payment } \\
\text { Method }\end{array}$ & $\begin{array}{l}\text { Credit/ } \\
\text { Debit } \\
\text { card \& } \\
\text { Cash }\end{array}$ & $\begin{array}{l}\text { Credit /Debit } \\
\text { \&Payd } \\
\text { through } \\
\text { Apps }\end{array}$ & $\begin{array}{l}\text { Credit } \\
\text { Debit card \& } \\
\text { Cash } \\
\text { Electronic } \\
\text { Money }\end{array}$ \\
\hline $\begin{array}{l}\text { Suitable } \\
\text { place }\end{array}$ & $\begin{array}{l}\text { Retails } \\
\text { shop/ } \\
\text { Superma } \\
\text { rket }\end{array}$ & $\begin{array}{l}\text { Retails shop } \\
\text { / Supermarket }\end{array}$ & Retails shop \\
\hline
\end{tabular}

The above table shows the key differences between 3 similar systems. The tags used by NCR SelfServ and Snabble to identify information are barcodes, while the tags used by Regi-Robo ${ }^{\mathrm{TM}}$ are RFID tags. By using RFID tag, the efficiency will be better than using Barcode. This is because the barcode scanner needs to directly aim at the barcode just can read the information of the product. The most troublesome thing is that customers need to scan all barcodes individually, which is time consuming. On the contrary, the RFID tag does not need to be aligned with the RFID reader and the reading speed of the RFID tag is very fast. It can read about 40 RFID tags at the same time. In addition, the use of RFID has higher security than barcodes, because if the barcode is torn or damaged, the product cannot be scanned, and its data is easy to be copied and counterfeited. However, RFID tags are covered by plastic, which is very rugged and durable, and its data can be encrypted. Among these 3 systems, only Snabble has a mobile application, which is why it is more efficient than NCR SelfServ, because although it also requires customers to scan items one by one, but this process is done when customers are shopping and it allow customer to pay directly through the program. However, if customers use NCR SelfServ, they need to scan the items one by one at the self-checkout station to make payment. At present, NCR SelfServ and Snabble have been used in retail stores and supermarkets. Instead, Regi-Robo ${ }^{\mathrm{TM}}$ needs a special shopping basket and is still under development, so it is only used by retailers. Therefore, based on this situation, shows that there is a need to develop a self-checkout system that implemented with RFID for Malaysia supermarket.

\subsubsection{Overview of the proposed system}

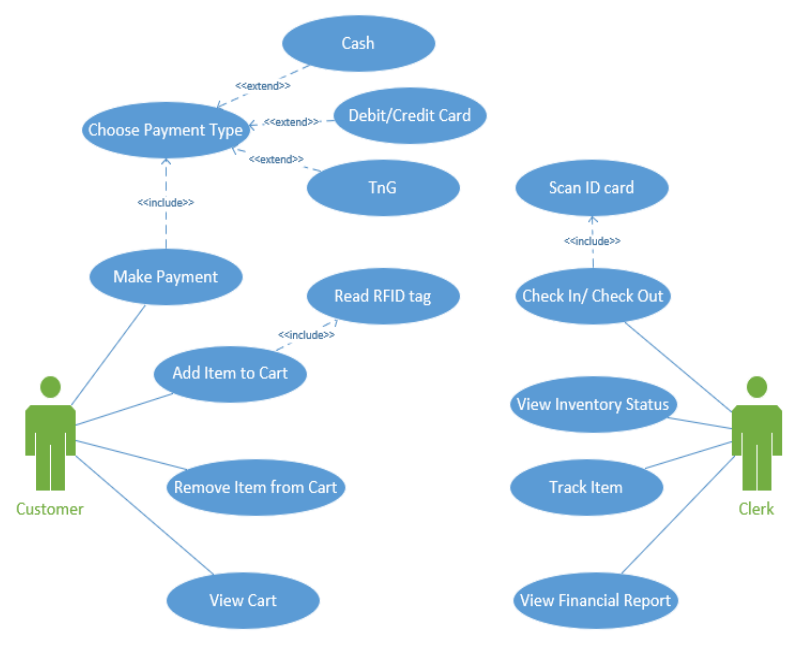

Figure 4 Use Case Diagram of the System

Figure 4 shows that the proposed system with RFID technology. According to the use case diagram, there is enough basic functions of self-service shopping in this proposed system for customer, such as viewing item lists, making payments and so on. Customers can directly take the product and put it directly into their shopping cart. At the end of their shopping, they just need to place the shopping cart in a specific area of the RFID reader, the system will directly read the information on all RFID tags inside and display it on a screen. Then the customer needs to make the payment in this specific area before they can walk out from the supermarket, otherwise if the RFID reader detects an unpaid item, an alarm will sound. For merchants, when the alarm sounds, the RFID tag on the unpaid item will immediately locate them to know the specific location of that item. Merchants can also use the system to check inventory information at any time through the RFID tag on the item to help prevent internal theft. In addition, they can use the system view daily financial 
reports and to check in or check out by using their employee ID cards.

\section{METHOD}

This research will use quantitative and qualitative research methods to conduct an in-depth study of the problems that caused decrease in income of merchants who use the self-checkout system. 100 customers who shop in Malaysia's supermarkets which equipped with selfcheckout systems will be selected as the target of this research. The main reason for choosing this research population is that they are direct users of the system. The selection of the customer was based on the systematic sampling method that belongs to probability sampling, because this method does not need to have a list of all customers in advance, and the exit order of customers is essentially random [40], so if continue to implement this method, can collect different type of customers' survey in different days and time periods, by this shows that it can provide a representative sample of customers.

This research will use a face-to-face survey method to collect data, because this method has a higher response rate and helps visitors get answers more accurately [17], like screening questions, such as gender or race When the interviewee was unable to provide false information. The survey will consist of 7 questions with 5-point Likert scales and 3 open questions, it will distribute to every fifth customer who leaves a supermarket equipped with a selfcheckout system. The data collection will be conducted until there are 100 customers' survey results.

After the survey results are collected, the researchers will eliminate missing data and outliers to identify any data points that may affect the accuracy of the results. Then, analyze the remaining quantitative data, generate charts, and summarize them into different descriptive statistics such as average, median, frequency, etc. [27] For the qualitative data collected in the open question, look for basic observations or patterns, find specific words or ideas that continue to appear in the survey, and then integrate and list the response categories. In the process, it needs to ensure that the data analysis and results reliability and validity, and finally look for possible and reasonable explanations of the results, and sort them out. [31]

\section{DISCUSSION}

After the supermarket uses the self-checkout system, the problem of increased thefts has caused many unnecessary expenditures in the supermarket, which greatly harmed their interests that also contrary to the original intention of the self-checkout system being intended: "To save business operating expenses". By using RFID technology to improve the self-checkout system, the system can scan goods faster and more accurately through RFID tags. When a customer passes through the RFID reader door, if there is something unpaid, the reader will make a sound, which will notice the guard and staff on duty. Besides that, RFID is a tracking technology, so by using RFID tags to replace the original barcodes on products, in addition to allowing RFID readers to automatically scan all products in a short period of time, merchants can also track the status of products [38], which will not give the thief any chance. Compared with the existing similar self-checkout systems, by implementing RFID can minimize their problems. For example, the barcode self-checkout system of Malaysia Tesco and Snabble. The self-checkout system that implements RFID can allow customers to operate faster and easier than them. By RFID tag and reader, they do not have to scan the goods one by one, and it also reduces the possibility that customers do not know how to operate the system. In addition, the proposed system is applied in the supermarket, which is customer will buy a plenty of goods that compare with the Regi-Robo ${ }^{\mathrm{TM}}$ from Panasonic that only using in retail shop is more suitable. By implementing RFID technology in existing self-checkout service not only can improve the speed, quality of selfcheckout goods in supermarket and also can minimizing loss and theft. This can significantly improve anti-theft capabilities and make payment faster than ever. Therefore, the research is valuable in term of minimizing the problem.

\section{CONCLUSION}

This paper proposes the combination of self-checkout system and RFID technology so that it can be used in supermarkets to solve the problem of increased theft rate of supermarket after using the self-checkout system. Through RFID, it can not only scan all items quickly and accurately, but also support merchants to track the location of inventory and items. Once a theft occurs, it is also easy to track the real-time location of the object. However, the current RFID technology in Malaysia is not mature enough and not well known to the public. At present, the best RFID technology used in Malaysia is the RFID TAG of the highway toll system, and the rest are still under development. With the further popularization of RFID, it can also be used in supermarket parking systems and attendance systems. For example, RFID technology can be used to automatically identify incoming and outgoing vehicles without stopping the car or RFID employee attendance system, which can automatically sense attendance without touching the machine. By this, can improve the efficiency and use of the mall.

\section{ACKNOWLEDGMENTS}

Highest appreciation to Asia Pacific University, Malaysia for the opportunity on the article publication. 


\section{REFERENCES}

[1] Abdullah Ertugb, Hulya Turkcan, Ufuk Cebecia, Exploring the determinants of intention to use selfcheckout systems in supermarket chain and its application, 2020, pp. 1027-1036 DOI: https://doi.org/10.5267/j.msl.2019.11.007

[2] A. Mehmood, Han He, Xiaochen Chen, A. Vianto, V. Vianto, Oğuz 'Oz' Buruk, J. Virkki, "ClothFace: A Passive RFID-Based Human-Technology Interface on a Shirtsleeve", Advances in Human-Computer Interaction, 2020, DOI: https://doi.org/10.1155/2020/8854042

[3] Adrian Beck Self-Checkout In Retail: Measuring the Loss, 2003, DOI: https://doi.org/10.13140/RG.2.2.14100.55686

[4] A. Firdaus, A Sai Krishna, Ch Lokesh, K Preethi, G Manmadha Rao. RFID Based Smart Trolley for Automatic Billing System, 2020, DOI: 10.35940/ijeat.A2401.069520

[5] Al-Hakmani, A. K. S., \& Sajan, A. Design and Implementation of a Smart Shopping Trolley Using RFID Technology. Journal of Student Research, 2020, DOI: https://doi.org/10.47611/jsr.vi.978

[6] A. Mercurio, B. Elbel, M. Bragg, N. Rodriguez, O. Martinez. Supermarket retailers' perspectives on healthy food retail strategies: in-depth interviews, 2018, DOI: https://doi.org/10.1186/s12889-018-59174

[7] A. Szymkowiak, J. J Turner. An analysis into early customer experiences of self-service checkouts: Lessons for improved usability, 2019, DOI: https://doi.org/10.2478/emj-2019-0003

[8] A. Mehmood, M. Ahmad, M. Shahroz, Muhammad Faheem Mushtaq, Saleem Ullah. IoT-Based Smart Shopping Cart Using Radio Frequency Identification, 2020,

DOI: https://doi.org/10.1109/ACCESS.2020.2986681

[9] A. Bayraktar, E. Yılmaz and Ş. Erdem. Using RFID Technology for Simplification of Retail Processes, 2011, DOI: https://doi.org/10.5772/20822

[10] Cesar, G.R.-Gonzalez, J. R.-Rosero, M. Ausecha. RFID Applications and Security Review. Computation, 2021, DOI: https://doi.org/10.3390/computation9060069
[11] Dr. J. Ramya Customer experience in supermarkets and hypermarkets - A comparative study, 17, 2015, pp 116-123

[12] Elliot Brenhouse. Self-checkout system with anti-theft deactivation device, 2010

[13] F. Chetouane. An Overview on RFID Technology Instruction and Application, 2015, pp.382-387 DOI: https://doi.org/10.1016/j.ifacol.2015.06.111

[14] G. Mortimer \& P. Dootson The economics of selfservice checkouts , 2017

[15] H. Ham, Martinus, Metta Saridewi Wahab, Yudi. Data Transmission Using RFID System on Smart Shopping Carts for Checkout Process Efficiency in Supermarket at Indonesia, vol 179, 2021, pp. 902-912, DOI: https://doi.org/10.1016/j.procs.2021.01.080.

[16] TH Haider, Salim Alrikabi, Naseer Ali Husieen, Saif Alsaidi Iman Kadhim Ajlan. Smart Shopping System with RFID Technology Based on Internet of Things, 2020, DOI: https://doi.org/10.3991/ijim.v14i04.13511

[17] James K. Doyle Face-to-Face Surveys , 2014 DOI: https://doi.org/10.1002/9781118445112.stat06686

[18] J. Chanchaichujit, N. S. M. Charmaine, Sreejith Balasubramanian. A systematic literature review on the benefit-drivers of RFID implementation in supply chains and its impact on organizational competitive advantage, Cogent Business \& Management, 2020, DOI: https://doi.org/10.1080/23311975.2020.1818408

[19] J. Mihułowicz, Węglarski, M., P. Factors Affecting the Synthesis of Autonomous Sensors with RFID Interface. Sensors, 2019, DOI: https://doi.org/10.3390/s19204392

[20] J.K Kwak. Empirical Analysis on Comparison between Self-checkout and Regular Staffed-checkout lanes in a Poland Retail Store, 2020, 8(1), pp. 56-61

[21] J.W Siah, Soo-Fen Fam. Reuse Intention of Selfcheckout Service Quality in Malaysia Hypermarket, 2018, pp. 485-495. DOI: https://doi.org/10.4314/jfas.v10i6s.202

[22] K.T Krause, Ulrike Vanessa Mueller System and Method for Mobile Device Self-Checkout for Retail Transactions with Loss Protection, 2016

[23] Kamal Ali Alezabi, Mohamed Yusoff1, Mohamad Khairi Ishak, Zainatul Yushaniza. The Role of RFID in Green IoT: A Survey on Technologies, Challenges 
and a Way Forward, 6(1), 2021, pp. 17-35 DOI: https://doi.org/10.25046/aj060103

[24] Katie French. Shoppers steal £3.2billion from selfservice tills every year with nearly a quarter of Britons admitting to taking at least one item without paying for it, 2017

[25] Lauren Thomas How to perform systematic sampling, 2020

[26] M. Donelli, OrcID, V. Mulloni, Chipless RFID Sensors for the Internet of Things: Challenges and Opportunities, 2020 ,

DOI: https://doi.org/10.3390/s20072135

[27] María-Victoria Bueno-Delgado, Francesc Burrull and Pablo Pavón- Mariño Case Study: Installing RFID Systems in Supermarkets, 2011 DOI: https://doi.org/10.5772/64972

[28] Manu Bhatia Your Guide to Qualitative and Quantitative Data Analysis Methods, 2018

[29] M. Bhattacharya. Impact of RFID on the Retail Value Chain: An Exploratory Study Using a Mixed Method Approach, 2012, pp. 36-49. DOI: https://doi.org/10.4067/S0718-27242012000400003

[30] Michael B.Persky. Multiple Self-checkout system having integrated payment device, 2004

[31] Muhammad Raqib Aiman Bin Rosnizam, Mui H K, Muhammad Ekmal Haikal Bin Mohammad Akhir, Misha Shahqira, Muhammad Amril Hanif, Bin Mohd Yusoff, Roland Satrya Budiman, Aisha Mohammad Alajmi Market Opportunities and Challenges: A Case Study of Tesco, 2019, DOI: https://doi.org/10.32535/jcda.v3i2.807

[32] Nancy Gibson A Step-By-Step Guide To Qualitative Data Analysis, 2003

[33] Martinez, O., Rodriguez, N., Mercurio, A, M. Bragg \& B. Elbel. Supermarket retailers' perspectives on healthy food retail strategies: in-depth interviews. BMC Public Health, 2018 DOI: https://doi.org/10.1186/s12889-018-5917-4

[34] Panasonic RFID Based Walk-through Checkout Solution for Future Retail, 2019

[35] Patrick Queisler IKEA To Offer Mobile SelfScanning And Self-Checkout With Snabble, 2019

[36] Samantha Khor Tesco Introduced Self-Checkout Machines In One Of Its Stores \& We Can't Wait To Try It Out, 2015
[37] Sima Ajami and Rajabzadeh. Radio Frequency Identification (RFID) technology and patient safety, 2013, pp. 809-813.

[38] S. L. Ting, Albert H. C. Tsang, Y. K. Tse A Framework for the Implementation of RFID Systems, 2013, DOI: https://doi.org/10.5772/56511

[39] Snabble Scan, Pay, Done - With Snabble , 2020

[40] Springer Radio-frequency Identification (RFID): Technology and Applications. [Online] pp 163-194. 2010, DOI: https://doi.org/10.1007/978-1-84996-0175_5

[41] Raghunath Arnab, in Survey Sampling Theory and Applications, 2017

[42] Ravi Panja, Ye Zhou, Leif Chastaine Dynamic product tracking system using RFID, 2009

[43] R.K. Srivastava Changing retail scene in India, International Journal of Retail \& Distribution Management [online] Vol. 36 No. 9, 2008 pp. 714721.

DOI: https://doi.org/10.1108/0959055081089095

[44] Vishwajeet V. Jituri RADIO FREQUENCY IDENTIFICATION (RFID) AND EASE OF LIFEDOI, 2020, DOI: https://doi.org/10.29121/granthaalayah.v8.i8.2020.81 1

[45] Wu, L., Liu, S., Zhao, B. et al. The research of the application of the binary search algorithm of RFID system in the supermarket shopping information identification. J Wireless Com Network 2020, https://doi.org/10.1186/s13638-019-1343-2

[46] Z. Guo, K. Yu, Y. Li, G. Srivastava, and J. C. -W. Lin, "Deep Learning-Embedded Social Internet of Things for Ambiguity-Aware Social Recommendations", IEEE Transactions on Network Science and Engineering, doi: 10.1109/TNSE.2021.3049262.

[47] L. Tan, N. Shi, K. Yu, M. Aloqaily, Y. Jararweh, “A Blockchain-Empowered Access Control Framework for Smart Devices in Green Internet of Things", ACM Transactions on Internet Technology, vol. 21, no. 3, pp. 1-20, 2021,https://doi.org/10.1145/3433542.

[48] Yu, K., Arifuzzaman, M., Wen, Z., Zhang, D. and Sato, T., 2015. A key management scheme for secure communications of information centric advanced metering infrastructure in smart grid. IEEE 
transactions on instrumentation and measurement, 64(8), pp.2072-2085.

[49] Chu, S.I., Liu, B.H. and Nguyen, N.T., 2019. Secure AF relaying with efficient partial relay selection scheme. International Journal of Communication Systems, 32(15), p.e4105.

[50] Seyhan, K., Nguyen, T.N., Akleylek, S. and Cengiz, K., 2021. Lattice-based cryptosystems for the security of resource-constrained IoT devices in post-quantum world: a survey. Cluster Computing, pp.1-20.

[51] Kowsalya, T., Babu, R.G., Parameshachari, B.D., Nayyar, A. and Mehmood, R.M., 2021. Low Area PRESENT Cryptography in FPGA Using TRNGPRNG Key Generation. CMC-COMPUTERS MATERIALS \& CONTINUA, 68(2), pp.1447-1465.

[52] Pham, V.T., Nguyen, T.N., Liu, B.H. and Lin, T., 2021, March. Minimizing latency for multiple-type data aggregation in wireless sensor networks. In 2021 IEEE Wireless Communications and Networking Conference (WCNC) (pp. 1-6). IEEE.

[53] Parameshachari, B.D., Panduranga, H.T. and liberata Ullo, S., 2020, September. Analysis and computation of encryption technique to enhance security of medical images. In IOP Conference Series: Materials Science and Engineering (Vol. 925, No. 1, p. 012028). IOP Publishing.

[54] Kumar, T.M., Reddy, K.S., Rinaldi, S., Parameshachari, B.D. and Arunachalam, K., 2021. A Low Area High Speed FPGA Implementation of AES Architecture for Cryptography Application. Electronics, 10(16), p.2023.

[55] N. Shi, L. Tan, W. Li, X. Qi, K. Yu, "A BlockchainEmpowered AAA Scheme in the Large-Scale HetNet", Digital Communications and Networks, https://doi.org/10.1016/j.dcan.2020.10.002.

[56] Subramani, P., Rajendran, G.B., Sengupta, J., Pérez de Prado, R. and Divakarachari, P.B., 2020. A block bidiagonalization-based pre-coding for indoor multipleinput-multiple-output-visible light communication system. Energies, 13(13), p.3466.

[57] Bhuvaneswary, N., Prabu, S., Karthikeyan, S., Kathirvel, R. and Saraswathi, T., 2021. Low Power Reversible Parallel and Serial Binary Adder/Subtractor. Further Advances in Internet of Things in Biomedical and Cyber Physical Systems, p.151. 